\title{
How companies' good deeds encourage consumers to adopt pro-social behavior
}

\author{
Simona Romani \\ Department of Business and Management, LUISS Guido Carli, Rome, \\ Italy, and \\ Silvia Grappi \\ Department of Economics, University of Modena and Reggio Emilia, \\ Modena, Italy
}

Pro-social behavior
Received 19 June 2012 Revised 6 April 2013 Accepted 7 May 2013

\begin{abstract}
Purpose - This paper aims to investigate the effects of company corporate social responsibility (CSR) initiatives on two consumers' pro-social behaviors closely related to the social cause promoted by the company, such as consumers donating money and volunteering time. In addition, the role of moral elevation as a mediating variable in such relationships is tested.

Design/methodology/approach - After an exploratory study, the authors tested the role of moral elevation as a mediator that facilitates the effects of company CSR activities in social domains on two specific types of pro-social behavior displayed by consumers: donating money and volunteering time for the same cause sponsored by the company. The authors conducted two quantitative studies to test their hypotheses. In Study 1, they considered the two pro-social behaviors as intentions; in Study 2, they analyzed them as actual behaviors. In both studies, the authors conducted controlled experiments administered in the field. By using experimental and control conditions, they were able to manipulate corporate responsible actions in social contexts, and a mediational analysis was conducted.

Findings - The authors results show that moral elevation mediates the positive relationship between the CSR activity and consumer intention to donate (actual consumer donating behavior) to social causes, and the CSR activity and volunteering intention (actual volunteering behavior).

Originality/value - This paper contributes to furthering CSR theory by showing the positive effects of company CSR initiatives on two pro-social "secondary" outcomes and the mediating role played by moral elevation. Important implications for the role of CSR are derived for companies and society in general.
\end{abstract}

Keywords Consumer pro-social behavior, CSR activity, Moral elevation

Paper type Research paper

\section{Introduction}

Corporate social responsibility (CSR), or "a commitment to improve community well-being through discretionary business practices and contributions of corporate resources" (Kotler and Lee, 2005, p. 3), is a central theme in the dialogue between companies and consumers (Nielsen, 2012). However, to formulate, implement and evaluate effective CSR strategies in the marketplace, it is essential to make an accurate

The authors thank the Associate Editor and the anonymous reviewers for their useful comments and suggestions. Both authors contributed equally to this manuscript.

\section{3}

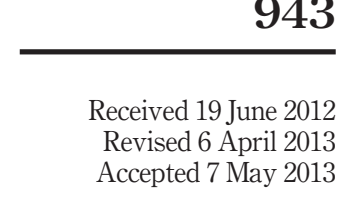
(1) 
EJM

$48,5 / 6$

944 analysis of consumers' reactions to firms' CSR initiatives. In doing so, it is important to start considering the potentially multifaceted impact of CSR initiatives (Bhattacharya and Sen, 2004a). In fact, in addition to their "primary" impact on the brand and company, CSR initiatives can also influence other "secondary" outcomes related to both the partner organizations (e.g. non-profit) and the main cause or social issue addressed by the company's CSR efforts. For example, examining the case of the cross-sector partnership between Home Depot and Habitat for Humanity, Bhattacharya and Sen (2004b) observe that this partnership is capable not only of influencing consumers' perceptions and responses toward Home Depot and its products, but also consumers' donations and volunteer work for Habitat for Humanity and issues related to housing for the underprivileged.

Although extant research has examined CSR actions' impact on consumers' evaluations of products and their behavioral intentions toward the company, (Du et al., 2007; Sen et al., 2006), very little attention has been given to investigating how corporate actions induce more general consumer responses toward the main causes or social issues associated with the company's CSR efforts. An interesting exception is represented by Lichtenstein et al. (2004), who provide evidence that company CSR activities not only affect customers' purchase behavior, but also their donations to corporate-supported, non-profit organizations, with a mediating role played by customer - corporate identification. However, as Bhattacharya and Sen (2004b) point out, companies need a better understanding of these "secondary" social outcomes of CSR if they are interested in increasing the social return on their CSR investments. Moreover, Bhattacharya et al. (2009) report the need for a more precise understanding of the consumers' different possible responses to CSR initiatives and the several underlying processes driving such responses. In particular, it is possible to recognize that the extant models tend to overlook the relationships between company CSR activities and "secondary" social outcomes as well as their possible explanations.

Our paper aims to contribute to CSR theory by paying particular attention to the effects of company CSR initiatives on two pro-social "secondary" outcomes closely related to the social cause promoted by the company, such as consumers donating money and volunteering time to the same cause. In addition, we test the effect of moral elevation as a mediating variable in such relationships. We suggest that moral elevation is an important driver of consumers' pro-social responses to CSR initiatives. Moral elevation is the positive emotion elicited when observing others behaving in a virtuous or commendable way. Experiencing moral elevation initiates action tendencies, like wishing to emulate the moral exemplar and acting pro-socially (Haidt, 2000, 2003). We expect that moral elevation mediates the effects of perceived CSR on consumers' pro-social reactions: company CSR activities can elicit feelings of moral elevation in consumers, which encourage them to engage in donating and volunteering for social causes closely associated with the CSR issues sponsored by the company.

The rest of the paper is organized as follows: in the next section, we draw on literature to establish boundaries and contents of moral elevation. Next, we develop a qualitative study to determine the important role of moral elevation in the CSR context. We then present the key hypotheses of our research and conduct two quantitative studies to test the mediating role of moral elevation between the company CSR activity toward its community and two specific consumers' pro-social behaviors: donating and volunteering for the same CSR issue sponsored by the company. These two pro-social 
behaviors are considered as intentions in Study 1 and as actual behaviors in Study 2 . Finally, we conclude with a discussion of our research findings and their implications.

\section{Moral elevation}

Along with gratitude, moral elevation is one of the moral emotions that Haidt (2003) calls "other praising". Similar to other emotions, it has been described as a set of related components that includes an eliciting event, physical changes, feelings and motivations for a certain type of action.

Moral elevation is elicited by acts of charity, kindness, loyalty, self-sacrifice or any other strong display of virtue (Haidt, 2003). It can be considered a typical emotional response to "moral beauty" or human goodness and appears to be the opposite of social disgust.

According to Haidt (2003), felt moral elevation initiates action tendencies, like wishing to become a better person and acting pro-socially. The results of several studies by Algoe and Haidt (2009), using recall, video induction, event-contingent diary and letter-writing methods to induce moral elevation, reveal the following: participants generally report feeling inspired and uplifted and - of central importance here motivated to perform pro-social and affiliated actions themselves. Landis et al. (2009) also present a positive correlation between the self-reported frequency of experiencing moral elevation and self-reported altruistic behavior. Freeman et al. (2009) demonstrate that moral elevation increases donations to a Black-oriented charity and attenuates the negative effects of the social dominance orientation's group-based dominance component. Schnall et al. (2010) and Cox (2010) also report results that support the hypothesis that pro-social responses are tangible behavioral effects of moral elevation. In addition, these positive behavioral effects are more likely to occur in a domain linked to the context in which moral elevation is experienced (Cox, 2010) and are usually felt by people whose moral identity is mostly self-defining (Aquino et al., 2011). Finally, Schnall and Roper (2012) provide evidence of an empowerment effect of moral elevation, showing that this positive emotion can avert the danger of moral licensing (among others, Mazar and Zhong, 2010; Sachdeva et al., 2009). In their experiment, in fact, feelings of moral elevation provide people with the motivation to act on their moral beliefs rather than licensing them to relax their moral strivings and engage less in pro-social behavior.

These aforementioned studies provide sufficient evidence that witnessing altruistic behavior elicits moral elevation, which in turn promotes a pro-social orientation and leads to increased altruism. Therefore, this particular emotion could be essential in explaining consumers' responses to CSR in a social context. However, to date, all evidence has been derived from basic psychology research under controlled conditions, typically with student samples. Thus, the role of moral elevation in CSR contexts is yet to be investigated. Given this lack of research, an exploratory study is needed in this early stage of the project to establish the boundaries and contents of this key construct in the CSR context. As observed by Batra et al. (2012), most marketing research tends to substitute the vast body of psychology literature on a specific topic for basic exploratory research, which leads to disagreements among scholars and different conceptualizations. The use of qualitative research in this preliminary phase can be of central importance, as illustrated later. 
EJM

$48,5 / 6$

946

\section{Companies' CSR activities and consumer moral elevation: preliminary qualitative evidence}

Do people experience moral elevation when they witness companies performing significant social responsibility acts? If so, how can the elicitation of this emotion be explained? Does it make any difference to individuals' subsequent pro-social behaviors?

Given that very little is known about moral elevation elicited by companies' CSR activities, in this preliminary qualitative study, we solicited consumers' narrative accounts of such experiences. Participants $(N=56)[1]$ were asked to write about a specific positive case when they had witnessed or heard about a company manifesting a higher or better moral nature. They then answered specific questions about changes in their thoughts, action tendencies or motivations and behaviors. All respondents were able to provide a narrative demonstrating that, despite many negative ethical collapses in the business world, a great number of virtuous actions still occur.

Common themes in participants' narratives were identified and discussed among researchers using procedures suggested by Spiggle (1994). These themes were then classified into three categories:

(1) situations that elicit the emotion of moral elevation in the CSR context and associated feelings;

(2) changes in the thought-action repertoire; and

(3) behavioral consequences associated with these changes[2].

Situations that elicit the emotion of moral elevation in the CSR context and associated feelings

The situations most cited as causing positive emotional feelings of moral elevation involved companies whose agenda of sustainability and general corporate responsibility is not only central to their business strategy but also a critical driver of business growth (Mish and Scammon, 2010; Smith et al., 2010). A wide selection of CSR initiatives undertaken by such companies - especially in the domains of product, environment, human rights, employee well-being and community support - featured in the respondents' narratives. A particularly powerful and detailed example captures the essence of these situations:

The case of Dove really touched me! I have to admit that I really appreciate its social mission in trying to change people's stereotypical views of female beauty. This is something really central to our lives! Many of women's problems derive from the unrealistic way in which they are portrayed in advertising, fashion, and the media. It's time to stop with these images that reduce women's self-esteem and self-confidence about the way they look. I really feel strongly positive and moved by this company's manifestation of a high moral nature! (F, 28).

\section{Changes in the thought-action repertoire}

Companies often claim CSR to be at the heart of their activities. However, in most cases, the transition of being a responsible and sustainable business is an ongoing process and they are exposed to a variety of criticisms from political, environmental and human rights activists if they fail to fulfill the elevated aims they formally espoused (Wagner et al., 2009). Consequently, when people witness or hear from a reliable source about a company's particular virtuous act, they commonly find themselves being pleasantly surprised and emotionally touched. Some respondents reported that their views of 
companies are changing and becoming more optimistic. This is far removed from the idea that businesses' only social obligation is to make profits and pay taxes. They announced their intentions to support these companies by purchasing their products or services and by displaying other forms of advocacy. Moreover, respondents especially reported their desire to become better people by committing themselves to becoming more virtuous, as reported here:

This company has really inspired me and motivated me to seriously examine my everyday behavior and make changes where needed and within my ability; it has changed my way of thinking about environmental protection. I have realized I can't go on doing nothing; I have to do my bit (M, 35).

\section{Behavioral consequences associated with these changes}

The orientation illustrated earlier appears to have an important effect on the relationship between a company and society in general. In fact, respondents described their growing loyalty to the company:

This company merits staying in the market; it deserves consumers' trust and purchases. These are two ways of rewarding it for its virtuous behavior. If this kind of information were to reach consumers, I think many of them would be ready to support the company. In my own small way, I try to spread the word by saying positive things about the company to people I meet $(\mathrm{F}, 45)$.

However, some narratives also reported an adjustment in respondents' behavior in social contexts, most often related to the domain in which moral elevation was experienced, as clearly illustrated here:

I believe this company has inspired and taught me about environmental issues. Now I am definitely more concerned about products and their impact. I am much more sensitive to these issues. I have recently started to participate in meetings organized by local environmental organizations and I have noticed that I am becoming much more active than in the past (F, 42).

The respondents' narratives clearly show that moral elevation is experienced when they are confronted by virtuous corporate social and environmental action. Witnessing good moral actions by companies can trigger strong positive emotions of moral admiration, which change people's thought-action repertoire and increase the likelihood that they not only show affiliative behavior toward the company, but also that they engage in social causes in the same sphere as the company's CSR initiatives. Several respondents reported that companies devoted to environmental concerns have influenced them to pay more attention to issues related to this topic.

It therefore appears that corporate virtuous support of certain causes can motivate individuals to undergo some forms of virtuous behavior modification themselves. Moreover, the positive emotion of moral elevation may be a powerful but understudied mechanism able to explain this change.

\section{Company CSR activities, consumers' feelings of moral elevation and consumers' pro-social behaviors: two quantitative studies}

Considering both the theoretical literature illustrated earlier and the preliminary exploratory evidence, we hypothesize and test the role of moral elevation as a missing mediator facilitating CSR activities' effects on consumers' pro-social behaviors. In line with the literature (Lichtenstein et al., 2004), and to test the mediating role of moral 
EJM $48,5 / 6$

948
Figure 1.

The effect of the manipulation on donating and volunteering behaviors via feelings of moral elevation elevation as rigorously as possible, our conceptual approach also includes consumer-company identification as a co-mediator, without formally hypothesizing its role. This variable represents the felt degree of overlap between consumers' and the organization's identity (Bergami and Bagozzi, 2000).

In CSR contexts, consumers can perceive companies' attention to and resources spent on ethical, environmental and social issues to prevent or relieve harm to people; the positive emotion of moral elevation can result from these examples of virtuous, commendable behaviors. Given this emotion's moral motive function illustrated earlier, the consumers should then be motivated to behave morally or pro-socially themselves. Specifically, we expect that consumers, who experience feelings of moral elevation resulting from companies' CSR initiatives for the local communities in which they operate, will be more likely to engage in pro-social acts; for the purposes of this study, they are measured according to the amount of money they donate or time they volunteer to the same communities.

These two behaviors are a subset of typical pro-social acts which can be considered a form of exchange with a formal non-profit organization and can occur as a spontaneous or planned event in a safe environment with minimal personal risk (Drollinger, 2010). The main difference between these two behaviors is that the exchange happens directly in the case of volunteering and indirectly in the case of donating money. In fact, in contrast to the relative privacy and general anonymity of money donation, volunteers often meet face-to-face with recipients and their activities can require more energy and initiative (Lee et al., 1999). In this study, we investigate both these behaviors as intentions (Study 1) and as actual behaviors (Study 2), and hypothesize the following (Figure 1):

H1. Consumers' feelings of moral elevation will mediate the relationship between the CSR activity toward the local community and consumers' intention to donate (consumers' actual donation) to social causes related to the same community.

H1a. The greater the CSR activity toward the local community, the greater the felt moral elevation.

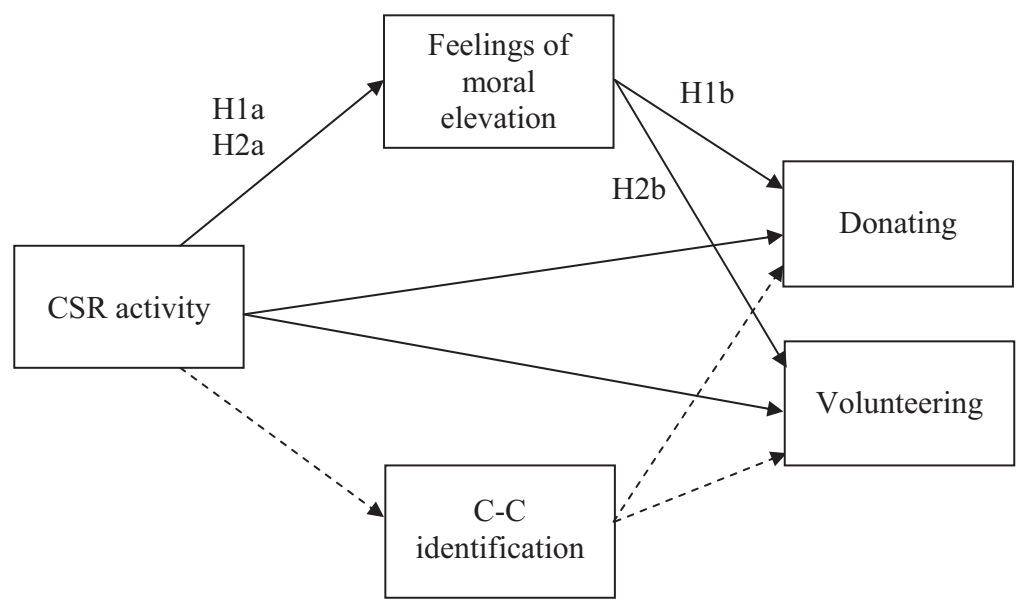


$H 1 b$. The greater the felt moral elevation, the greater the consumers' intention to donate (consumers' actual donation) to social causes related to the same community.

Pro-social behavior

H2. Consumers' feelings of moral elevation will mediate the relationship between the CSR activity toward the local community and consumers' intention to volunteer (consumers' actual volunteering) to the same community.

H2a. The greater the CSR activity toward the local community, the greater the felt moral elevation.

$H 2 b$. The greater the felt moral elevation, the greater the consumers' intention to volunteer (consumers' actual volunteering) to the same community.

\section{Study 1}

In Study 1, we investigated the positive effect of company CSR initiatives on consumers' intentions to donate and volunteer. In addition, we examined the possibility that the effect of CSR initiatives on such pro-social intentions can be explained in terms of felt moral elevation.

Study design. By using experimental and control conditions, we were able to manipulate corporate responsible actions in social contexts. Both the mediating and dependent variables were measured variables. To examine treatment effects, we ran a mediational analysis (Preacher and Hayes, 2008). The variables in our design can be summarized as:

(1) A manipulated dichotomous CSR variable indicating exposure to either the experimental or control condition. The manipulated CSR practices were positive actions in a social context (see late).

(2) Two continuous mediating variables: one consisting of multiple items for the positive emotion of moral elevation and another measuring the consumer-company identification.

(3) Two continuous outcome variables referring to donating and volunteering intentions for community building movements.

Stimulus materials. Narrative versions of the experimental and control conditions were developed, pretested and subsequently revised. The positive stimulus narrative provided participants with a detailed description of the company and its responsible social actions. The positive narrative concerned a company operating in organized distribution that set up a support scheme for the community called the "time bank". Although the name of the company was fictitious, the narrative was based on real corporate practices actually realized by existing companies at a certain time. The control narrative used descriptive content identical to that in the positive narratives, except for the omission of corporate responsible actions. (Additional details are available from the authors upon request).

Scenarios are often used in the psychology literature to induce emotions (Roseman, 1991). This is done because of the difficulty of and ethical issues associated with directly manipulating people's emotions.

Sample and procedure. Potential adult respondents were approached randomly in central shopping areas and asked to complete the questionnaire. A final sample of 140 
EJM 48,5/6

950
Italian interviewees was obtained. The participant sample has the following characteristics: 57 men ( 41 per cent) and 83 women ( 59 per cent); 18.6 per cent between 18 and 24 years old, 20.4 per cent between 25 and 34 years old, 21.0 per cent between 35 and 44 years old, 18.8 per cent between 45 and 54 years old, 16.4 per cent between 55 and 64 years old and 4.8 per cent over 65 years old. Respondents with a university education accounted for 35.7 per cent of the sample, followed by those with high school qualifications (52.2 per cent) or less (12.1 per cent).

Three items were also used to measure respondents' social desirability (Fisher, 1993). The three items, measured on a 7-point Likert scale, were "Usually, I do not rebel against people in authority even though I know they are wrong", "I am always courteous, even to people who are disagreeable" and "I have never been irked when people expressed ideas very different from my own" $(\alpha=0.67)$. These items were then used as indicators of a social desirability variable $(\mathrm{M}=3.52, \mathrm{SD}=1.20)$. One-sample $t$-test analysis comparing the sample mean and value mean of the scale (4) confirmed that respondents exhibited low levels of social desirability $(t=-4.75, p<0.01)$.

Measures. Mediating variable. Moral elevation was measured using three 7-point items, anchored by "very weak" and "very strong" in response to the question, "Based on the information in the scenario, please express the degree to which you felt the following emotions", with the emotion descriptions of "touched", "inspired" and "moved"[3]. Factor analysis showed that the moral elevation items loaded on one factor, with loadings ranging from 0.64 to 0.92 and an alpha of 0.81 . Other non-moral emotion descriptors were included to disguise the intent of our mediating variable, and they loaded on different factors. To measure identification with the company, we used the two items from Bergami and Bagozzi (2000). Identification items loaded on one factor, factor loadings were 0.88 and 0.91 and the inter-correlation was 0.85 .

Outcome variables. We measured these variables using items on a 7-point scale, anchored by "not at all probable" and "highly probable". To measure participants' likelihood to donate, we asked them how likely/unlikely they would be to:

(1) donate money to social causes related to the community;

(2) benefit causes related to the community; and

(3) donate goods and services to social causes related to the community.

A factor analysis verified that the donating items loaded on one factor, ranging from 0.71 to 0.95 with an alpha of 0.90 . To measure participants' volunteering intention, we asked how likely/unlikely respondents would be to adopt the following three behaviors:

(1) join community building movements;

(2) support residents to work individually and collectively toward community improvements; and

(3) form citizen-based groups to address local issues of concern.

A factor analysis verified that the joining and volunteering variable items loaded on one factor, ranging from 0.89 to 0.93 with an alpha of 0.93 .

Analyses and results. To test our mediation hypotheses, we used the bootstrapping bias-corrected confidence interval procedure. We ran the Preacher-Hayes script (2008) for multiple mediation. We ran two models for each dependent variable (donating and volunteering intentions): 
(1) In Model 1, we considered the mediating role of one variable, namely, identification with the company, which, according to the literature, plays a role in explaining how consumers' perception of CSR activities influences their relevant outcomes (Lichtenstein et al., 2004).

(2) In Model 2, we tested the mediating role of feelings of moral elevation, "nesting" this variable in Model 1. The comparison of the two models (Bagozzi, 1984) certifies the increment obtained by adding moral elevation.

The direct and indirect effects of donating intentions are presented in Table I. The $F$-ratio test (Bagozzi, 1984) confirms the important role of moral elevation, attesting the significant increment to $R$-squared from Model 1 to $\operatorname{Model} 2(F$-ratio $(\mathrm{df})=17.96(1,136)$; $p<0.001)$.

$H 1$ predicted that consumers' feelings of moral elevation mediate the relationship between the CSR activity and their intention to donate to social causes. We found a positive and significant direct effect of consumers' perception of the CSR activity on their feelings of moral elevation $\left(a_{2}=0.96, p<0.00\right)$, which supports H1a. Moreover, we found a significant positive direct effect of consumers' feelings of moral elevation on their intention to donate $\left(b_{2}=0.40, p<0.00\right)$, thereby supporting $H 1 b$. At the same time, we found significant direct effects for identification (Table I). With regard to the mediating effect, we observed a significant indirect effect of consumers' perception of the CSR activity on their donating intention via their feelings of moral elevation $\left(a_{2} b_{2}=\right.$ $0.39, p<0.00)$ with a 95 per cent confidence interval excluding zero (0.17-0.70). Therefore, the general hypothesis $H 1$ is supported. As for the direct effect of the CSR activity on consumers' intention to donate to social causes $\left(c^{\prime}=0.47\right)$, this relationship is still significant in the mediation model $(p=0.04)$, showing a complementary mediation

\begin{tabular}{lccccc}
\hline $\begin{array}{l}\text { Model with two mediators: identification and moral } \\
\text { elevation }\end{array}$ & $\begin{array}{c}\text { Unstandardized } \\
\text { estimates }\end{array}$ & SE & $t$ & $p$-value \\
\hline $\begin{array}{l}\text { Direct effects } \\
\text { Manipulation on donating (total) (c) }\end{array}$ & 1.11 & 0.26 & $4.28^{* * * *}$ & 0.00 \\
Manipulation on donating (direct) (c') & 0.47 & 0.22 & $2.16^{* *}$ & 0.04 \\
Manipulation on identification (a1) & 0.60 & 0.28 & $2.11^{* *}$ & 0.03 \\
Manipulation on moral elevation (a2) & 0.96 & 0.20 & $4.75^{* * *}$ & 0.00 \\
Identification on donating (b1) & 0.43 & 0.06 & $6.67^{* * *}$ & 0.00 \\
Moral elevation on donating (b2) & 0.40 & 0.09 & $4.50^{* * * *}$ & 0.00 \\
Indirect effects & & & & \\
Manipulation on donating via the two mediators (c-c') & 0.64 & 0.18 & $3.49^{* * * *}$ & 0.00 \\
Manipulation on donating via identification (a1b1) & 0.25 & 0.13 & $2.02^{*}$ & 0.04 \\
Manipulation on donating via moral elevation (a2b2) & 0.39 & 0.12 & $3.29^{* * * *}$ & 0.00
\end{tabular}

Bootstrap 95 per cent confidence intervals for conditional indirect effect-bias corrected and accelerated (BCa)

$\begin{array}{lcr}\text { Manipulation on donating via the two mediators } & \text { Lower } & \text { Upper } \\ \text { Manipulation on donating via identification } & 0.28 & 1.04 \\ \text { Manipulation on donating via moral elevation } & 0.03 & 0.56 \\ \text { M } & 0.17 & 0.70\end{array}$

Table I. Donating intention: results of mediation tests using bootstrapping biascorrected procedure 
EJM $48,5 / 6$

952

Table II.

Volunteering intention: results of mediation tests using bootstrapping biascorrected procedure
(Zhao et al., 2010). We also found significant mediating effects of the CSR activity on consumers' donating intention via identification[4] (Table I).

Table II shows the direct and indirect effects for volunteering intentions. The $F$-ratio test (Bagozzi, 1984) confirms the significant increment to $R$-squared from Model 1 to Model $2(F$-ratio $(\mathrm{df})=11.53(1,136) ; p<0.001)$.

H2 predicted that consumers' feelings of moral elevation mediate the relationship between the CSR activity and their volunteering intention. We observed a positive and significant direct effect of the CSR activity on consumers' feelings of moral elevation $\left(a_{2}=0.96, p<0.00\right)$, supporting $H 2 a$. Likewise, consumers' feelings of moral elevation had a positive and significant effect on their intention to volunteer $\left(b_{2}=0.31, p<0.00\right)$, which supports $H 2 b$. At the same time, we found significant direct effects for identification (Table II). With regard to the mediating effect, we observed a significant indirect effect of consumers' perception of the CSR activity on volunteering intention via consumers' feelings of moral elevation $\left.\left(a_{2} b_{2}=0.30, p<0.00\right)\right)$, with a 95 per cent confidence interval excluding zero (0.14-0.56). Therefore, the general hypothesis $H 2$ is supported. Regarding the direct effect of the CSR activity on consumers' intention to volunteer $\left(c^{\prime}=0.19\right)$, the relationship is not significant in the mediation model $(\phi=0.40)$, showing an indirect-only mediation (Zhao et al., 2010). We also found significant mediating effects of the CSR activity on consumers' volunteering intentions via identification[5] (Table II).

Study 1 produced preliminary evidence for the effect of company CSR initiatives on consumers' donating and volunteering intentions. More importantly, this effect was mediated by feelings of moral elevation following exposure to the company's social initiatives. Subsequently, the findings were consistent with our hypotheses. The results

Model with two mediators: identification and moral elevation

Unstandardized estimates SE $t \quad p$-value

Direct effects

Manipulation on volunteering (total) (c)

Manipulation on volunteering (direct) (c')

Manipulation on identification (a1)

Manipulation on moral elevation (a2)

Identification on volunteering (b1)

Moral elevation on volunteering (b2)

Indirect effects

Manipulation on volunteering via the two mediators

$\left(\mathrm{c}-\mathrm{c}^{\prime}\right)$

Manipulation on volunteering via identification (a1b1)

Manipulation on volunteering via moral elevation (a2b2)

$\begin{array}{llll}0.77 & 0.27 & 2.89 * * * & 0.00 \\ 0.19 & 0.23 & 0.84 & 0.40 \\ 0.60 & 0.28 & 2.11^{* *} & 0.03 \\ 0.96 & 0.20 & 4.75^{* * *} & 0.00 \\ 0.47 & 0.07 & 6.96^{* * *} & 0.00 \\ 0.31 & 0.10 & 3.32^{* * *} & 0.00\end{array}$

Bootstrap 95 per cent confidence intervals for conditional indirect effect-bias corrected and accelerated (BCa)

$\begin{array}{lll}\text { Manipulation on volunteering via the two mediators } & 0.24 & 0.97\end{array}$

$\begin{array}{lll}\text { Manipulation on volunteering via identification } & 0.03 & 0.60\end{array}$

Manipulation on volunteering via moral elevation $\quad 0.14 \quad 0.56$

Model summary for DV Model: $R^{2}=0.41 ; F(\mathrm{df})=31.71(3,136) ; p=0.00$

Notes: $* * p<0.05$, **** $p<0.01$ 
moreover showed the significant mediating effect of identification in the relationship between the CSR activity and consumers' volunteering and donating intentions, thereby replicating and extending the work of Lichtenstein et al. (2004).

\section{Pro-social behavior}

Study 2

The objective of Study 2 was to address some potential limitations of Study 1 and, by doing so, fortify the evidence for $\mathrm{H} 1$ and $H 2$. First, in light of the extensive evidence that people are more willing to help when they are in a positive mood (Isen, 1987; Baron, 1997), it is important to rule out the possibility that positive affect plays a role in mediating the effect of corporate CSR initiatives on consumers' pro-social acts. A multi-item measure of happiness was included in this new study to address this issue.

There is another potential important limitation of Study 1 in that it measures intentions rather than actual behaviors. In this second study, we assessed actual monetary donations and volunteering behaviors. Assessing these real behaviors is vital because people may express willingness to help without actually helping (Batson, 1991). Finally, a different company CSR initiative is considered in this study - aiding the victims of the May 2012 earthquake in Italy - to examine the generalizability of our findings.

Stimulus materials. As in Study 1, we used the same study design running a controlled experiment administered in the field. Narrative versions of the experimental and control conditions were developed, pretested and revised after pretesting. In Study 1 , the text of the experimental condition was longer than that of the control condition. As this feature may have influenced the responses, we addressed this potential problem in Study 2 by structuring the two scenarios (i.e. the experimental and the control narratives) into texts of similar lengths. Specifically, the experimental narrative was based on information about the company CSR activities, while the control narrative supplied general information about the company without reference to any CSR activities. In this way, we were able to ensure that the results are not affected by length issues. The positive stimulus narrative provided participants with a detailed description of a company and its responsible social activities in support of the victims of the May 2012 earthquake in Emilia Romagna, a region of northern Italy. Although the name of the company was fictitious, the narrative was based on real corporate practices that were realized by existing companies. (Additional details are available from the authors upon request).

Sample and procedure. Potential adult respondents were approached randomly in central shopping areas and asked to complete the questionnaire. A final sample of 177 Italian interviewees was obtained. Two versions of the questionnaire were prepared: one with the donating behavior item presented before the volunteering behavior item and the other in reverse order, counterbalancing to control for possible order effects (Liu and Aaker, 2008). The participant sample has the following characteristics: 65 men (37 per cent) and 112 women (63 per cent); 26.6 per cent between 18 and 24 years old, 24.7 per cent between 25 and 34 years old, 15.1 per cent between 35 and 44 years old, 17.7 per cent between 45 and 54 years old, 9.4 per cent between 55 and 64 years old and 6.5 per cent over 65 years old. Respondents with a university education accounted for 31.3 per cent of the sample, followed by those with high school qualifications (56.8 per cent) or less (11.9 per cent). 
EJM $48,5 / 6$

954

Table III. Likelihood ratio tests
We also controlled for the respondents' social desirability (Fisher, 1993) ( $M=3.18$, $\mathrm{SD}=1.51, \alpha=0.72$ ). One-sample $t$-test analysis comparing the sample mean and value mean of the scale (4) confirmed that respondents exhibited low levels of social desirability $(t=-7.04, p<0.01)$. We also asked respondents to indicate how much they felt affected by the event on a 7-point scale $(\mathrm{M}=3.90, \mathrm{SD}=1.63)$. One-sample $t$-test analysis comparing the sample mean and value mean of the scale (4) confirmed that respondents were perceived to be affected by the event at a medium level $(t=-0.75, p=$ $0.46)$, and no difference was detected between the experimental and control groups $(t=$ $0.67, p=0.50)$.

Measures mediating variable. As in Study 1, moral elevation was measured using the three 7-point items "touched", "inspired" and "moved" (factor loadings ranging from 0.60 to $0.71 ; \alpha=0.87$ ), while happiness was measured using the items "delighted", "happy" and "joyful" (factor loadings ranging from 0.67 to $0.75 ; \alpha=0.91$ ). All these items were anchored by "very weak" and "very strong". To measure identification with the company, we used the two items from Bergami and Bagozzi (2000). The identification items loaded on one factor, factor loadings were 0.91 and 0.93 and the inter-correlation was 0.83 . We ran a confirmatory factor analysis on mediators (i.e. moral elevation, happiness and identification) to assess convergent and discriminant validity. The fit of the model was excellent $\left(\chi^{2}(\mathrm{df})=26.41(17)\right.$; comparative fit index $=0.99$; non-normed fit index $=0.99$; root mean square error of approximation $=0.05$; standardized root mean square residual $=0.03$ ), and likelihood ratio tests showed that the measures of all variables exhibited discriminant validity (Table III).

Outcome variables. To measure real donations, we asked participants to make a decision on how to allocate real money that they might win as a result of participation in the experiment. Participants were told that there would be a random draw wherein they would have a 1 per cent chance of winning $€ 50$; they could choose to keep the money for themselves or donate some or all of it to the same cause sponsored by the company CSR initiative. After reading these instructions, participants were asked to indicate how much (from 0 per cent to 100 per cent) of the $€ 50$ they would like to donate if they were chosen as a winner. Study instructions made it clear to participants that any money allocated by the winner to the cause would really be donated by the researchers. We treated this measure as a continuous variable in our analysis. The average percentage of the possible winnings that subjects of the experimental group $(\mathrm{M}=83.79$ per cent[6]; $\mathrm{SD}=13.64$ ) were willing to donate differs significantly from that of the control group $(\mathrm{M}=34.06$ per cent, $\mathrm{SD}=28.49)(t=13.92, p<0.00)$.

To measure real volunteering behavior, we asked participants if they would like to volunteer for the same cause sponsored by the company CSR initiative. If so, they were to include their personal e-mail addresses in order to be contacted within the next days and to organize the activities. Study instructions made it clear to participants that giving their e-mail addresses meant actively joining the volunteering project and that they

\begin{tabular}{lcc}
\hline & $\chi^{2}(\mathrm{df})$ & $\Delta \chi^{2}(\Delta \mathrm{df}) ; p$ \\
\hline Model without constrictions & $26.41(17)$ & - \\
Moral elevation = happiness & $56.21(18)$ & $29.80(1) ; p<0.01$ \\
Moral elevation = identification & $36.41(18)$ & $10.00(1) ; p<0.01$ \\
Happiness = identification & $37.82(18)$ & $11.41(1) ; p<0.01$ \\
\hline
\end{tabular}


would be contacted shortly with a detailed e-mail describing the volunteering activities that they would be expected to complete within the following month. We treated this measure as a dichotomous variable in our analysis. The number of respondents in the experimental group who agreed to give their personal e-mail addresses (52.4 per cent of respondents) differed significantly from that of the control group (36.5 per cent of respondents) $\left(\chi^{2}(\mathrm{df})=4.41(1), p=0.03\right)$.

Analyses and results. To test our mediation hypotheses, we used the bootstrapping bias-corrected confidence interval procedure. We ran the Preacher-Hayes script (2008) for multiple mediation. For each dependent variable, we ran the model testing the mediating role of the felt moral elevation, in parallel with other possible mediators (i.e. identification and happiness).

The direct and indirect effects of donating behavior are presented in Table IV. Consumers' feelings of moral elevation mediate the relationship between the CSR activity and the donating behavior to social causes. We found a positive and significant direct effect of consumers' perception of the CSR activity on their felt moral elevation $\left(a_{2}=1.94, p<0.00\right)$, which supports H1a. Moreover, we found a significant positive direct effect of consumers' feelings of moral elevation on their donating behavior $\left(b_{2}=\right.$ $2.61, p=0.05)$, thereby supporting $H 1 b$. At the same time, we found significant direct effects of consumers' perception of CSR activity on consumer identification $\left(a_{1}=0.59\right.$, $p=0.01)$ but not of identification on consumers' donating behavior $\left(b_{1}=-1.39, p=\right.$ 0.29). Regarding the other possible mediator, we found a significant direct effect of consumers' perception of the CSR activity on their feelings of happiness $\left(a_{3}=1.95, p<\right.$ $0.00)$, but no significant positive direct effects of this variable on their donating behavior $\left(b_{3}=-0.70, p=0.54\right)$.

With regard to the mediating effect, we observed a significant indirect effect of consumers' perception of the CSR activity on their donating behavior via consumers' feelings of moral elevation $\left(a_{2} b_{2}=2.41, p=0.05\right)$ with a 95 per cent confidence interval excluding zero (0.05-6.51). Therefore, the general hypothesis $H 1$ is supported. As for the direct effect of CSR activity on consumers' donating behavior to social causes, this relationship is still significant in the mediation model, showing a complementary mediation (Zhao et al., 2010). We did not find a significant mediating effect of the CSR activity on consumers' donating behavior via happiness $\left(a_{3} b_{3}=-1.37, p=0.54\right.$; 95 per cent confidence interval $=-3.13-6.12)$. In this case, identification also has no significant mediating effect on consumers' donating behavior $\left(a_{1} b_{1}=-0.81, p=0.32\right.$; 95 per cent confidence interval $=-0.66-3.11)[7]$ (Table IV).

Table $\mathrm{V}$ shows the direct and indirect effects on the dichotomous variable of actual volunteering behavior. We found that consumers' feelings of moral elevation mediate the relationship between the CSR activity and consumers' volunteering behavior. We observed a positive and significant direct effect of the CSR activity on consumers' feelings of moral elevation $\left(a_{2}=1.94, p<0.00\right)$, supporting $H 2 a$ and a significant positive direct effect of consumers' feelings of moral elevation on volunteering behavior $\left(b_{2}=0.36, p=0.03\right)$, which supports $H 2 b$. We found significant direct effects of consumers' perception of CSR activity on consumer identification $\left(a_{1}=0.59, p=0.01\right)$ and, in turn, of identification on consumer volunteering behavior $\left(b_{1}=0.30, p=0.05\right)$. Regarding the other possible mediator, we found a significant direct effect of consumers' perception of CSR activity on their feelings of happiness $\left(a_{3}=1.95, p<0.00\right)$ and a 


\section{EJM $48,5 / 6$}

Table IV. Donating behavior: results of mediation tests using bootstrapping biascorrected procedure

Model with multiple mediators: identification, moral elevation and happiness

Direct effects

Manipulation on donating (direct) (c')

956
Manipulation on donating (total) (c)

Manipulation on moral elevation (a2)

Manipulation on happiness (a3)

Identification on donating (b1)

Moral elevation on donating (b2)

Happiness on donating (b3)

Indirect effects

Manipulation on donating via the three mediators $\left(\mathrm{c}-\mathrm{c}^{\prime}\right)$

Manipulation on donating via identification (a1b1)

Manipulation on donating via moral elevation (a2b2)

Manipulation on donating via happiness (a3b3)

Bootstrap 95 per cent confidence intervals for conditional indirect effect-bias

Unstandardized estimates

$\begin{array}{rrcr}49.57 & 3.86 & 12.86^{* * *} & 0.00 \\ 49.34 & 3.28 & 15.03^{* * *} & 0.00 \\ 0.59 & 0.22 & 2.69^{* * *} & 0.01 \\ 1.94 & 0.21 & 9.32^{* * *} & 0.00 \\ 1.95 & 0.25 & 7.74^{* * *} & 0.00 \\ -1.39 & 1.31 & -1.07 & 0.29 \\ 2.61 & 1.42 & 1.97^{* *} & 0.05 \\ -0.70 & 1.15 & -0.61 & 0.54 \\ & & & \\ 0.23 & 2.08 & 0.11 & 0.91 \\ & & & \\ -0.81 & 0.82 & -1.00 & 0.32 \\ 2.41 & 1.39 & 1.96^{* *} & 0.05 \\ & & & \\ -1.37 & 2.22 & -0.62 & 0.54\end{array}$
corrected and accelerated (BCa)

Lower Upper

Manipulation on donating via the three mediators $\quad-4.76 \quad 3.82$

Manipulation on donating via identification $\quad-0.66 \quad 3.11$

Manipulation on donating via moral elevation $\quad 0.05 \quad 6.51$

Manipulation on donating via happiness $\quad-3.13 \quad 6.12$

Model summary for DV Model: $R^{2}=0.57 ; F(\mathrm{df})=57.85(4,167) ; p=0.00$

Notes: $* * p<0.05, * * * p<0.01$

significant direct effect of this variable on their volunteering behavior $\left(b_{3}=-0.27, p=\right.$ 0.04).

With regard to the mediating effect, we observed a significant indirect effect of consumers' perception of the CSR activity on their volunteering behavior via consumers' feelings of moral elevation, with a 95 per cent confidence interval excluding zero $\left(a_{2} b_{2}=\right.$ 0.72 ; confidence interval $=0.14 ; 1.47)$. Therefore, the general hypothesis $H 2$ is supported. The direct effect of the CSR activity on consumers' volunteering behavior is still significant in the mediation model, showing a complementary mediation (Zhao et al., 2010). We also found significant mediating effects of the CSR activity on consumers' volunteering behavior via identification $\left(a_{1} b_{1}=0.28\right.$; confidence interval $=$ 0.01-0.66). Regarding happiness, we did not find a significant mediating effect of the CSR activity on consumers' volunteering behavior $\left(a_{3} b_{3}=-0.52\right.$; confidence interval $=$ -1.14 to 0.04$)[8]$ (Table V).

The results were consistent with the hypotheses. Participants who were exposed to the positive CSR initiative contributed more in terms of money and time than participants exposed to the control condition. Moreover, these effects were mediated by feelings of moral elevation but not happiness. With regard to the role of identification, the results showed a significant mediating effect on consumers' volunteering behaviors, but not on their donating behaviors. These mixed results will be discussed later. 


\begin{tabular}{|c|c|c|c|c|c|}
\hline $\begin{array}{l}\text { Model with multiple mediators: identification, } \\
\text { moral elevation, and happiness }\end{array}$ & $\begin{array}{l}\text { Unstandardized } \\
\text { estimates }\end{array}$ & SE & $t / z$ & $p$-value & $\begin{array}{l}\text { Pro-social } \\
\text { behavior }\end{array}$ \\
\hline \multicolumn{6}{|l|}{ Direct effects } \\
\hline Manipulation on volunteering (total) (c) & 1.56 & 0.43 & (z) $3.63^{* * *}$ & 0.00 & \multirow{8}{*}{957} \\
\hline Manipulation on volunteering (direct) (c') & 1.02 & 0.32 & (z) $3.24 * * *$ & 0.00 & \\
\hline Manipulation on identification (a1) & 0.59 & 0.22 & (t) $2.69 * * *$ & 0.01 & \\
\hline Manipulation on moral elevation (a2) & 1.94 & 0.21 & (t) $9.32^{* * * *}$ & 0.00 & \\
\hline Manipulation on happiness (a3) & 1.95 & 0.25 & (t) $7.74 * * *$ & 0.00 & \\
\hline Identification on volunteering (b1) & 0.30 & 0.15 & (z) $1.96 * *$ & 0.05 & \\
\hline Moral elevation on volunteering (b2) & 0.36 & 0.16 & (z) $2.25^{* *}$ & 0.03 & \\
\hline Happiness on volunteering (b3) & -0.27 & 0.13 & $(z)-2.03$ & 0.04 & \\
\hline \multicolumn{6}{|c|}{ Bootstrap results for indirect effects on dichotomous $D V$} \\
\hline \multicolumn{6}{|c|}{$\begin{array}{l}\text { Bootstrap } 95 \text { per cent confidence intervals for conditional indirect effect-bias corrected and } \\
\text { accelerated (BCa) }\end{array}$} \\
\hline & Effect & Boot SE & Lower & Upper & \multirow{6}{*}{$\begin{array}{l}\text { Table V. } \\
\text { olunteering behavior: } \\
\text { lts of mediation tests } \\
\text { g bootstrapping bias- } \\
\text { corrected procedure }\end{array}$} \\
\hline $\begin{array}{l}\text { Manipulation on volunteering via the three } \\
\text { mediators }\left(c-c^{\prime}\right)\end{array}$ & 0.48 & 0.28 & -0.02 & 1.08 & \\
\hline $\begin{array}{l}\text { Manipulation on volunteering via identification } \\
\text { (a1b1) }\end{array}$ & 0.28 & 0.17 & 0.01 & 0.66 & \\
\hline $\begin{array}{l}\text { Manipulation on volunteering via moral elevation } \\
\text { (a2b2) }\end{array}$ & 0.72 & 0.34 & 0.14 & 1.47 & \\
\hline Manipulation on volunteering via happiness (a3b3) & -0.52 & 0.28 & -1.14 & 0.04 & \\
\hline \multicolumn{5}{|c|}{$\begin{array}{l}\text { Model summary for DV Model: }-2 \mathrm{LL}=215.14 \text {; R2CoxSnell }=0.14 \text {; R2Nagelkrk }=0.20 ; n=177 \\
\text { Notes: } * * p<0.05, * * *<0.01\end{array}$} & \\
\hline
\end{tabular}

\section{General discussion}

Using methodologically diverse studies and both measures for intentions and actual behaviors, this paper proposes and empirically demonstrates the positive effect of company CSR initiatives on two pro-social "secondary" outcomes strictly related to the social causes promoted by the company, such as consumers donating money and volunteering time. Moreover, this study empirically tests the importance of the affective aspects of moral elevation as mechanisms for understanding how and why CSR initiatives influence consumers' reactions in terms of giving - be it money or time. Positive company CSR actions are capable of engendering consumers' feelings of moral elevation that can, in turn, bring about an increase in their own pro-social behaviors. Specifically, this study demonstrates that people who are exposed to positive CSR practices are more likely to experience moral elevation and are therefore more willing to donate their money and/or time to the same cause that is sponsored by the company.

Additionally, it is worth noting that our research empirically replicates the key-mediating role of consumer-company identification in the "CSR actions - consumer pro-social reactions" link, even regarding fictitious company cases. These results are explicable because, although we used fictitious company names in our study, we based our scenarios on detailed descriptions of the company and its activities. We were thus able to give readers a specific idea about the company, favoring the possible match between the consumers' self and the company's identity, and thus simultaneously fostering consumers' identification with it. Such identification proves that it drives consumers' pro-social intentions and actual volunteering behaviors, but not their actual 
EJM

$48,5 / 6$

958 donating behaviors. Donating behaviors, which are characterized by a monetary sacrifice and indirect exchanges (Lee et al., 1999), probably require the presence of a real company to activate the effect of consumer-company identification (Lichtenstein $e t$ al., 2004; Study 1). This prerequisite seems unnecessary regarding actual volunteering behaviors, which are characterized by direct exchanges and possibly direct control by individuals (Lee et al., 1999). Further research should focus on establishing the boundary conditions for the effect of consumer-company identification on pro-social behaviors, that is, under what circumstances or for which type of people does this effect exists.

\section{Theoretical implications}

Our findings provide valuable theoretical and empirical insights into previous research which called for the uncovering of both the "secondary" social outcomes of CSR (Bhattacharya and Sen, 2004b) and further mechanisms to explain the effectiveness of such CSR activities (Bhattacharya et al., 2009). Specifically, Bhattacharya et al. (2009, p. 258) observe that "it is becoming increasingly clear that in order to explain and predict the outcomes of the CSR activity with any degree of certainty, we need a more precise understanding of the underlying processes that drive those returns".

Inspired by the recent call for greater consideration of the role of emotions in CSR research (see among others, Ketola, 2008), this study introduces and tests the positive role of feelings of moral elevation in driving consumers' pro-social responses in terms of donating and volunteering. Until now, the extant models (Lichtenstein et al., 2004) have focused largely on cognitive aspects and have completely overlooked the emotional side of consumer behavior; however, in doing so, research has failed to capture the full effects of CSR activities and systematically underestimates the true social return of such initiatives. In addition, the extensive extant research, which argues that people react to moral issues with moral emotions (Haidt, 2001, 2007), also makes the inclusion of moral elevation in CSR theory compelling, especially given the evidence that moral elevation inspires people to perform good deeds.

Moreover, this study supports the idea of an empowerment effect of moral elevation (Schnall and Roper, 2012). It confirms that this positive emotion can avert the danger of moral licensing. In our study, companies' moral behavior was not found to provide individuals with credentials that can license subsequent morally questionable behaviors, as reported recently by Kouchaki (2011) [9].

\section{Limitations and future research directions}

A first limitation of this research and an important area for future research is the relationship between consumers' pro-social behaviors and company CSR activities. This paper focused on pro-social behaviors closely related to the CSR initiative; however, future studies should test the boundaries of this effect considering, for example, pro-social behaviors in unrelated domains. Second, further research could focus on actual company cases, overcoming limitations as a result of using fictitious company names, especially with regard to the role played by consumer-company identification in real donating behaviors. Third, further consideration should be given to constructs that leverage moral elevation in CSR contexts at both an individual and company level. For example, the capacity for moral elevation could be moderated by morally relevant traits, such as empathy, individual values or gender. At a company level, the distinctiveness (from competitors), concreteness or reputation of the company's supported cause could 
be constructs capable of influencing the effects of the CSR actions. Finally, further research should explicitly verify the appraisal processes behind felt moral elevation, including goal congruence, agent intentions and agent motives.

Pro-social behavior

\section{Practical implications}

As consumers' feelings of moral elevation may increase their likelihood of displaying not only affiliative behaviors toward the company but also of engaging in social causes in the same area as the company's CSR initiatives, some important implications can be derived for managers involved in CSR activities. First of all, managers should try to orient consumers' positive feelings toward supporting the company in terms of purchasing products and services. Moreover, and more importantly, they should also orient these feelings toward other forms of supportive behavior (e.g. positive word-of-mouth, providing feedback, proselytizing others, etc.) directed at improving the company-consumer relationship and, in general, the company's image and reputation (Bhattacharya et al., 2009; Du et al., 2007). In addition, our findings open avenues for exploring a broader issue related to the role of CSR for companies and society in general. Traditionally, CSR is acknowledged as a marketing tool, which is often used to build a good company reputation or image (Vaaland et al.,2008). Our research shows that, at the same time, CSR should be considered a tool to affect consumers' evaluations and behaviors more widely, encompassing actions not only directly connected to the company implementing positive CSR strategies, but to the entire society.

These findings therefore highlight the central role of CSR activities in driving important pro-social changes in society. Moreover, they encourage companies to consider how their activities can deliver value beyond their primary interest, reaching and benefiting the whole society. An interesting example relating to this is represented by a recent CSR campaign started by COOP, the largest retailer in Italy. Italians are among the top consumers of bottled water per person in the world (in 2011 third, after Arab Emirates and Mexico). Each person in Italy drinks approximately 196 liters of bottled water per year. Evidently, this has a big environmental impact. To try to cut back on the pollution caused not only by all the plastic bottles, but also by transporting the water across long distances, COOP has started a CSR initiative directed at convincing consumers to stop buying bottled water and rather switch to tap water, or to at least buy water that comes from a nearby area. The company hopes to strengthen its image as a "green" company interested in the environment, to improve its relationships with customers who can recognize the company's self-sacrifice for a greater good. However, it also hopes to spark the population's attention to the environmental concerns behind bottled water in the hope that they will modify their behavior and switch to tap water.

\section{Notes}

1. Participants were adults employed both in the private and public sectors in Italy. They were approached in several locations during their lunch break and were asked to participate in the research after explaining its purpose. The participant group had the following characteristics: 30 women and 26 men; 17.9 per cent between 18 and 24 years old, 26.8 per cent between 25 and 34 years old, 26.8 per cent between 35 and 44 years old, 14.3 per cent between 45 and 54 years old and 14.2 per cent over 55 years old. In total, 24 participants had a university degree, and the rest had a high school qualification. 


\section{$\mathrm{EJM}$ $48,5 / 6$}

\section{0}

2. The detailed methodology and additional illustrative quotations are available from the authors.

3. These emotion descriptors were adapted from Freeman et al. (2009) considering also the description of the moral elevation construct provided by Haidt $(2000,2003)$.

4. We verified whether these two indirect effects differ significantly. Because zero was contained in the 95 per cent confidence interval of the pairwise contrast $(-0.64 ; 0.16)$, the two specific indirect effects were not distinct in terms of magnitude. This finding strongly confirms the importance of introducing moral elevation as additional mechanism for explaining pro-social outcomes of CSR activity.

5. Because zero was contained in the 95 per cent confidence interval of the pairwise contrast $(-0.39 ; 0.42)$, the two specific indirect effects were not distinct in terms of magnitude.

6. This result is in line with existing research on actual monetary donation (Zhou et al., 2012).

7. The 95 per cent confidence intervals of the pairwise contrasts between identification and moral elevation $(-7.52 ;-0.23)$ and moral elevation and happiness $(2.05 ; 10.19)$ do not contain zero, thus the specific indirect effect through moral elevation is larger than the specific indirect effects through identification and through happiness, respectively. The 95 per cent confidence interval of the pairwise contrast between identification and happiness $(-5.37$; 5.60) contains zero and, consequently, they do not differ in magnitude.

8. Because zero was contained in the 95 per cent confidence interval of the pairwise contrast between identification and moral elevation $(-5.37 ; 5.60)$, the two specific indirect effects were not distinct in terms of magnitude. The 95 per cent confidence intervals of the pairwise contrasts between identification and happiness $(0.16 ; 1.61)$ and moral elevation and happiness $(0.16 ; 2.33)$ do not contain zero. Each specific indirect effect, through identification and elevation, is larger than the specific indirect effect through happiness.

9. It is worth noting that the absence of an effect of vicarious moral licensing in the context of our study could also derive from the moderate level of identification between individuals and the actor of the target behavior (in our case a fictitious company with its CSR initiatives). In our two quantitative studies, respondents' identification with the company is lower than the value mean of the measurement scale (4): in Study 1, the respondents' identification is 3.70 (SD = 1.36) $(t=-3.36, p<.01)$; in Study 2 , it is $3.22(\mathrm{SD}=1.27)(t=-5.25, p<.01)$.

\section{References}

Algoe, S.B. and Haidt, J. (2009), "Witnessing excellence in action: the "other-praising' emotions of elevation, gratitude and admiration", The Journal of Positive Psychology, Vol. 4 No. 2, pp. 105-127.

Aquino, K., McFerran, B. and Laven, M. (2011), "Moral identity and the experience of moral elevation in response to acts of uncommon goodness", Journal of Personality and Social Psychology, Vol. 100 No. 4, pp. 701-718.

Bagozzi, R.P. (1984), "Expectancy-value attitude models an analysis of critical measurement issues", International Journal of Research in Marketing, Vol. 1 No. 4, pp. 295-310.

Baron, R.A. (1997), "The sweet smell of [...] helping: effects of pleasant ambient fragrance on prosocial behaviour in shopping malls", Personality and Social Psychology Bulletin, Vol. 23 No. 5, pp. 498-503.

Batra, R., Ahuvia, A. and Bagozzi, R.P. (2012), "Brand love”, Journal of Marketing, Vol. 76 No. 2, pp. 1-16. 
Batson, D.C. (1991), The Altruism Question: Toward a Social-Psychological Answer, Erlbaum, Hillsdale, NJ.

Bergami, M. and Bagozzi, R.P. (2000), "Self-categorization, affective commitment and group self-esteem as distinct aspects of social identity in the organization", British Journal of Social Psychology, Vol. 39 No. 4, pp. 555-577.

Bhattacharya, C.B. and Sen, S. (2004a), "Measuring the effectiveness of corporate social initiatives: a consumer-centric perspective", in Kahn, B.E. and Luce, M.F. (Eds), Advances in Consumer Research, Vol. 31, Association for Consumer Research, Valdosta, GA.

Bhattacharya, C.B. and Sen, S. (2004b), "Doing better at doing good: when, why and how consumers respond to corporate social initiatives", California Management Review, Vol. 47 No. 1, pp. 9-24.

Bhattacharya, C.B., Korschun, D. and Sen, S. (2009), "Strengthening stakeholder-company relationships through mutually beneficial corporate social responsibility initiatives", Journal of Business Ethics, Vol. 85 No. 2, pp. 257-272.

Cox, K.S. (2010), "Elevation predicts domain-specific volunteerism 3 months later", The Journal of Positive Psychology: Dedicated to Furthering Research and Promoting Good Practice, Vol. 5 No. 5, pp. 333-341.

Drollinger, T. (2010), "A theoretical examination of giving and volunteering utilizing resource exchange theory”, Journal of Nonprofit and Public Sector Marketing, Vol. 22 No. 1, pp. 55-66.

Du, S., Bhattacharya, C.B. and Sen, S. (2007), "Reaping relational rewards from corporate social responsibility: the role of competitive positioning", International Journal of Research in Marketing, Vol. 24 No. 3, pp. 224-241.

Fisher, R.J. (1993), "Social desirability bias and the validity of indirect questioning", Journal of Consumer Research, Vol. 20 No. 2, pp. 303-315.

Freeman, D., Aquino, K. and McFerran, B. (2009), "Overcoming beneficiary race as an impediment to charitable donations: social dominance orientation, the experience of moral elevation, and donating behavior", Personality and Social Psychology Bulletin, Vol. 35 No. 1, pp. $72-84$.

Haidt, J. (2000), "The positive emotion of elevation", Prevention and Treatment, Vol. 3, Article 0003, posted March 7, 2000.

Haidt, J. (2001), "The emotional dog and its rational tail: a social intuitionist approach to moral judgment”, Psychological Review, Vol. 108 No. 4, pp. 814-834.

Haidt, J. (2003), "Elevation and the positive psychology of morality", in Keyes, C.L.M. and Haidt, J. (Eds), Flourishing: Positive Psychology and the Life Well-Lived, American Psychological Association, Washington, DC, pp. 275-289.

Haidt, J. (2007), “The new synthesis in moral psychology”, Science, Vol. 316 No. 5827, pp. 998-1002.

Isen, A.M. (1987), "Positive affect, cognitive processes and social behaviour", in Berkowitz, L. (Ed), Advances in Experimental Social Psychology, Academic Press, New York, NY, pp. 203-253.

Ketola, T. (2008), "A holistic corporate responsibility model: integrating values, discourses and actions”, Journal of Business Ethics, Vol. 80 No. 3, pp. 419-435.

Kotler, P. and Lee, N. (2005), Corporate Social Responsibility: Doing the Most Good for Your Company and Your Cause, Wiley \& Sons, Inc, Hoboken, NJ.

Kouchaki, M. (2011), "Vicarious moral licensing: the influence of others' past moral actions on moral behavior", Journal of Personality and Social Psychology, Vol. 101 No. 4, pp. 702-715.

Landis, S.K., Sherman, M.F., Piedmont, R.L., Kirkhart, M.W., Rapp, E.M. and Bike, D.H. (2009), "The relation between elevation and self-reported prosocial behavior: incremental validity 
EJM $48,5 / 6$

962 over the five-factor model of personality", Journal of Positive Psychology, Vol. 4 No. 1, pp. 71-84.

Lee, L., Piliavin, J.A. and Call, V.R.A. (1999), "Giving time, money, and blood: similarities and differences”, Social Psychology Quarterly, Vol. 62 No. 3, pp. 276-290.

Lichtenstein, D.R., Drumwright, M.E. and Braig, B.M. (2004), "The effect of corporate social responsibility on customer donations to corporate-supported nonprofits", Journal of Marketing, Vol. 68 No. 4, pp. 16-32.

Liu, W. and Aaker, J. (2008), “The happiness of giving: the time-ask effect”, Journal of Consumer Research, Vol. 35 No. 3, pp. 543-557.

Mazar, N. and Zhong, C. (2010), "Do green products make us better people?”, Psychological Science, Vol. 21 No. 4, pp. 494-498.

Mish, J. and Scammon, D.L. (2010), "Principle-based stakeholder marketing: insights from private triple-bottom-line firms", Journal of Public Policy and Marketing, Vol. 29 No. 1, pp. 12-16.

Nielsen (2012), “The global, socially-conscious consumer”, Nielsen Report, March.

Preacher, K.J. and Hayes, A.F. (2008), "Asymptotic and resampling strategies for assessing and comparing indirect effects in multiple mediator models", Behavior Research Methods, Vol. 4 No. 3, pp. 879-891.

Roseman, I.J. (1991), “Appraisal determinants of discrete emotions”, Cognition and Emotion, Vol. 5 No. 3, pp. 161-200.

Sachdeva, S., Iliev, R. and Medin, D.L. (2009), "Sinning saints and saintly sinners: the paradox of moral self-regulation”, Psychological Science, Vol. 20 No. 4, pp. 523-528.

Schnall, S. and Roper, J. (2012), "Elevation puts moral values into action”, Social Psychological and Personality Science, Vol. 3 No. 3, pp. 373-378.

Schnall, S., Roper, J. and Fessler, D.M.T. (2010), "Elevation leads to altruistic behavior, above and beyond general positive affect”, Psychological Science, Vol. 21 No. 3, pp. 315-320.

Sen, S., Bhattacharya, C.B. and Korschun, D. (2006), "The role of corporate social responsibility in strengthening multiple stakeholder relationships: a field experiment”, Journal of the Academy of Marketing Science, Vol. 34 No. 2, pp. 158-166.

Smith, N.C., Drumwright, M.E. and Gentile, M.C. (2010), “The new marketing myopia”, Journal of Public Policy and Marketing, Vol. 29 No. 1, pp. 4-11.

Spiggle, S. (1994), "Analysis and interpretation of qualitative data in consumer research”, Journal of Consumer Research, Vol. 21 No. 3, pp. 491-503.

Vaaland, T.I., Heide, M. and Grønhaug, K. (2008), "Corporate social responsibility: investigating theory and research in the marketing context", European Journal of Marketing, Vol. 42 Nos 9/10, pp. 927-953.

Wagner, T., Lutz, R.J. and Weitz, B.A. (2009), "Corporate hypocrisy: overcoming the threat of inconsistent corporate social responsibility perceptions", Journal of Marketing, Vol. 73 No. 6, pp. 77-91.

Zhao, X., Lynch, J.G.J.R. and Chen, Q. (2010), "Reconsidering baron and kenny: myths and truths about mediation analysis", Journal of Consumer Research, Vol. 37 No. 2, pp. 197-206.

Zhou, X., Wildschut, T., Sedikides, C., Shi, K. and Feng, C. (2012), "Nostalgia: The gift that keeps on giving", Journal of Consumer Research, Vol. 39 No. 1, pp. 39-50.

\section{About the authors}

Simona Romani is an Associate Professor in Consumer Behavior at Luiss Guido Carli, Rome (Italy). Prior to her position at Luiss, Simona served on the faculty at the University of Pisa (Italy). 
Simona's primary research interests concern consumer behavior and branding. Current projects explore the topics of brand activism, the "dark side" of consumer preferences, brand dislike, counterfeit consumption, consumer reactions to CSR and the processing of misleading advertising. Simona's work has been published in the International Journal of Research in Marketing, Journal of Business Ethics, Marketing Letters, Journal of Brand Management, Journal of Business Research, Journal of Product and Brand Management, Advances in Consumer Research and in various edited volumes.

Silvia Grappi is an Assistant Professor in Marketing at the University of Modena and Reggio Emilia (Italy). Her primary research interests are in the areas of consumer behavior and branding. Silvia's current research explores consumption of counterfeit luxury goods, consumers' negative emotions toward brands, consumer reactions to CSR and consumer behavior in the tourism industry. Silvia's work has been published in International Journal of Research in Marketing, Journal of Business Ethics, Tourism Management, Journal of Business Research, Journal of Brand Management, Advances in Consumer Research and in various edited volumes. Silvia Grappi is the corresponding author and can be contacted at: silvia.grappi@unimore.it

To purchase reprints of this article please e-mail: reprints@emeraldinsight.com Or visit our web site for further details: www.emeraldinsight.com/reprints 